\section{IDDF2020-ABS-0187 LAPAROSCOPIC EXTRACTION OF A RAPUNZEL: SAFE AND EFFECTIVE}

Veerabhadra Radhakrishna*, Mamatha Basavaraju. Bangalore Medical College and Research Institute, India

\subsection{6/gutjnl-2020-IDDF.112}

Background Rapunzel syndrome is a rare manifestation of trichobezoar characterized by extension of a mass of hair across pylorus into the small bowel. Only 40 odd cases have been reported in the literature to date. Most of the Rapunzels have been treated by laparotomy and a few by laparoscopic assistance. Reports on the complete laparoscopic extraction are scarce. We report a successful laparoscopic extraction of a Rapunzel in a 17-year-old girl.

Methods A 17-year-old girl presented with a history of pain abdomen and non-bilious vomiting for a month duration. The girl was studying in a residential school, and she had an urge to pull and eat her hair. Her vital examination was normal. Her weight was $23 \mathrm{~kg}$. There was a mass palpable in the epigastrium. Routine blood investigations were within normal limits. The radiological evaluation showed a non-homogenous opacity occupying the whole of the stomach, extending into the duodenum and jejunum suggestive of Rapunzel syndrome. A psychiatric evaluation revealed that she was in severe depression due to the death of her beloved one. Antidepressants were initiated and planned for surgery.

Results Under General anesthesia, she was placed in lithotomy position. A 5-mm subumbilical camera port was placed. Three 5 -mm operating ports were placed in the right hypochondrium, left lumbar, and epigastric regions. A $10 \mathrm{~cm}$ long anterior gastrotomy was done, the Rapunzel was released from the stomach wall all around and gently delivered into an endogenously made sturdy endobag. Extra care was taken to completely extract the Rapunzel and to avoid the spillage. The subumbilical port incision was extended on either side to bring out the mouth of the endobag. A sponge holding forceps was used to remove the trichobezoar in piecemealc

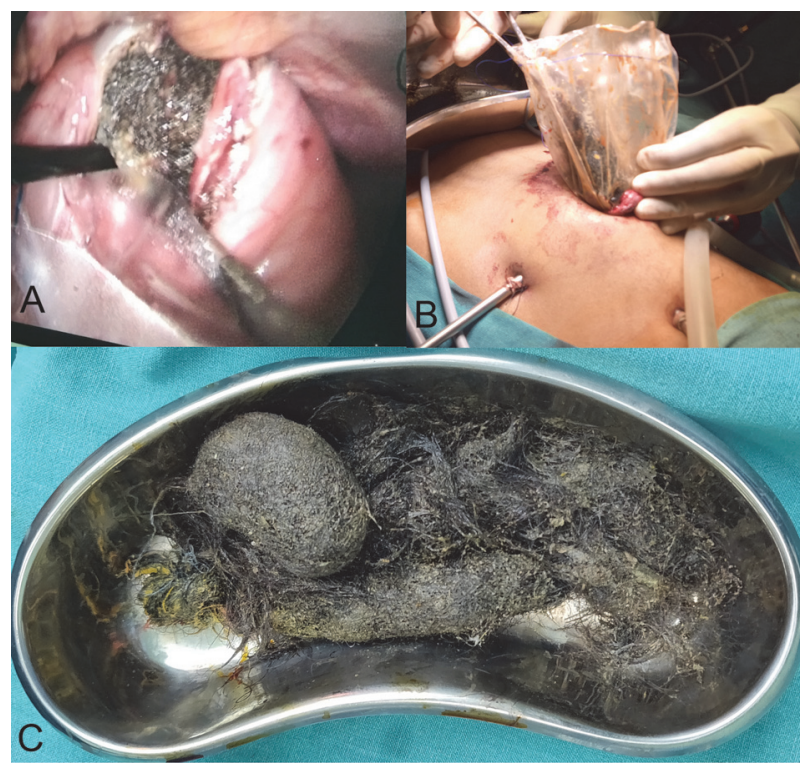

Abstract IDDF2020-ABS-0187 Figure 1 Anterior gastrostomy was done (A), Rapunzel delivered into an endobag and extracted via subumbilical port site by piecemeal with the endobag acting as wound protector (B and C) (figure 1). The patient was started on a liquid diet from the 2nd postoperative day, gradually escalated to a normal diet by 4th day, and discharged after psychiatric counseling and medications. She is on follow up for the past six months and currently asymptomatic.

Conclusions Complete extraction of a Rapunzel by laparoscopy is safe. A sturdy endobag prevents spillage and also acts as a wound protector.

\section{IDDF2020-ABS-0190 EFFICACY OF INFLIXIMAB TREATMENT ON THE MUCOSAL HEALING OF DIFFERENT INTESTINAL SEGMENTS IN PATIENTS WITH ILEOCOLONIC CROHN'S DISEASE} ${ }^{1}$ Pengyu Yang, 'Xiaolei Wang. 'Shanghai Tenth People's Hospital, Tongji University, China; ${ }^{2}$ Shanghai First People's Hospital Branch Hospital, China; 'Shanghai Tenth People's Hospital, Soochow University, China

\subsection{6/gutjnl-2020-IDDF.113}

Background Mucosal healing $(\mathrm{MH})$ is the key aim of the treat-to-target strategy for patients with Crohn's disease (CD). The efficacy of infliximab on $\mathrm{MH}$ in different ileocolonic segments is unclear. The aim of this study was to investigate endoscopic $\mathrm{MH}$ in different ileocolonic segments in patients with $\mathrm{CD}$ who received infliximab treatment.

Methods A retrospective, single-center study was performed in patients with active ileocolonic CD between January 2012 and December 2018. All patients underwent IFX treatment for at least 30 weeks. The $\mathrm{MH}$ of five ileocolonic segments was assessed by the Simple Endoscopic Score for CD (SES-CD) at baseline, week 14 and week 30. The SES-CD scores were analyzed by a mixed-effects model after the confounding factors were corrected.

Results A total of 101 eligible patients were included. The baseline endoscopic severity was similar across segments. At week 30, the greatest changes in SES-CD ulcer size and ulcerated surface were $-94.29 \%$ and $-94.32 \%$ both in the transverse colon $(P<0.0001)$, and the smallest changes were $67.88 \%$ and $-69.67 \%$ both in the terminal ileum $(P<0.0001)$ compared with the changes in the other segments. Stenosis mainly presented in the right colon $(12 / 29,41.38 \%)$. The change in SES-CD stenosis was $-6.25 \%$ in the right colon at week 30 compared with $-71.88 \%$ at week $14(\mathrm{P}=0.0030)$. At week 30, the transverse colon achieved the highest rate of complete $\mathrm{MH}(\mathrm{CMH})$ with $81.2 \%$, and the lowest $\mathrm{CMH}$ rate occurred in the terminal ileum with $45.6 \%$.

Conclusions Ileocolonic segments in Crohn's disease presented different endoscopic MH during IFX treatment. The transverse colon showed the highest $\mathrm{MH}$ rate, whereas the right colon had poor improvement in stenosis even underwent long-term IFX therapy.

\section{IDDF2020-ABS-0191 MULTIMODALITY MANAGEMENT OF BORDERLINE ADVANCED UNCINATE CARCINOMA AND POSTOPERATIVE GASTROJEJUNOSTOMY FISTULA}

Monika Gupta*. Manipal Hospital Jaipur Rajasthan India, India

10.1136/gutjnl-2020-IDDF.114 